\title{
Analysis on start up and heat transfer performance of mercury heat pipe under alternating heating power
}

\author{
Chongju $\mathrm{Hu}^{1,2,3}$, Xiuxiang Zhang ${ }^{3, *}$, Hongyan $\mathrm{Wang}^{3}$, Bo $\mathrm{Wu}^{3}$, Pinghua Zhang ${ }^{3}$ \\ ${ }^{1}$ Key Laboratory of Neutronics and Radiation Safety, Institute of Nuclear Energy Safety Technology, HFIPS, Chinese Academy of \\ Sciences, Hefei, Anhui 230031, China \\ ${ }^{2}$ University of Science and Technology of China, Hefei, Anhui 230027, China \\ ${ }^{3}$ Suzhou University, Suzhou, Anhui 234000, China
}

\begin{abstract}
Heat pipe may be affected by the high temperature heat source during operation, resulting in unsteady oscillation heating. In this paper, the influence of alternating power and period on the start-up and heat transfer performance of mercury heat pipe is studied by using the method of equivalent thermal resistance of heat pipe. The results are as follows:1) The start-up time of alternating power heating and steady-state power heating is basically equal; 2) For the alternating power heating, the steady-state temperature of heat pipe changes periodically, increasing the alternating period or the amplitude of alternating power will lead to the increase of the fluctuation amplitude of heat pipe temperature, and the influence of alternating period is greater than that of changing the amplitude of alternating power. 3) Under the condition of alternating power heating, the steady-state thermal resistance of heat pipe changes periodically. The fluctuation amplitude of steady-state thermal resistance of heat pipe increases with the increase of alternating period and alternating power amplitude, and the influence of alternating power amplitude is greater than that of alternating period.
\end{abstract}

\section{Introduction}

Heat pipe has been widely used in electronic industry ${ }^{[1]}$, energy industry ${ }^{[2]}$ and aerospace ${ }^{[3-4]}$, because of its good isothermal property, high reliability and no need to provide additional power. In recent years, there are many researches on the performance of heat pipe. Enke et al. Studied the transient response behavior of the axiallygrooved aluminum-ammonia heat pipe with the presence of non-condensable gas, and found that the presence of non-condensable gas will lead to the gradual deterioration of the heat pipe performance ${ }^{[5]}$. Wang et al. explored the influence of inclination angle and input power on the startup performance of high temperature potassium heat pipe, and discovered that the start-up performance is mainly affected by capillary heat transfer limit and viscous heat transfer limit under the condition of uniform and constant heat flow ${ }^{[6]}$. Teng et al. indicated that the swing conditions has little effect on the start-up performance of the sodium heat pipe, but it will cause a small range of periodic temperature fluctuations ${ }^{[7]}$. Miao et al experimentally analyzed the heat transfer performance for a Bent CopperWater Heat Pipe. It was demonstrated that the critical heat flux increases with increasing cooling temperature and the length of evaporator and condenser ${ }^{[8]}$.

The above research mainly focuses on the steady-state heat source heating, but the heat pipe during opearation may encounter heat source instability, which will lead to unsteady oscillatory heating. Xu et al. pointed out that the solar radiation intensity has a great influence on the operation of high temperature heat pipe receiver ${ }^{[9]}$. Shen et al. experimentally studied the heat transfer performance of triangle high temperature heat pipe with variable heat flux. The results showed that the alternating power has an important influence on the heat transfer of heat pipe ${ }^{[10]}$.

In a word, there are few reports about heat pipe under unstable heat source, especially for mercury heat pipe. In this paper, The start-up and heat transfer performance of a mercury heat pipe under periodic heat source was studied by using the equivalent thermal resistance method, which provides some theoretical guidance for understanding the operation of mercury heat pipe under unstable heat source.

\section{Theoretical models and verification ${ }^{[11]}$}

\subsection{Establishment of theoretical model}

The equivalent thermal resistance method is used to study the characteristics of mercury heat pipe, and the schematic diagram is shown in Figure. 1. Among of these, Figure a) shows the complete equivalent thermal resistance model. Where R8 represents the axial thermal resistance of the heat pipe wick and $\mathrm{R} 9$ represents the axial thermal resistance of the heat pipe wall. Due to these two thermal resistances are in parallel with other thermal resistances, and their values are much larger than other thermal resistances. In order to simplify the calculation, their influence is ignored in this paper. Figure b) shows a simplified equivalent thermal resistance diagram.

*Corresponding author: zhangxiuxiang86@163.com 
$Q_{1}$

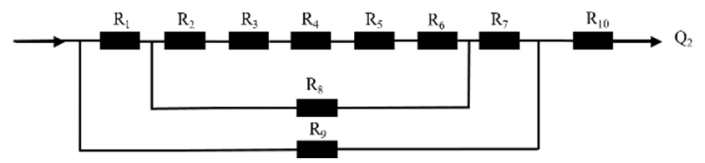

a) Complete model

$Q_{1}$

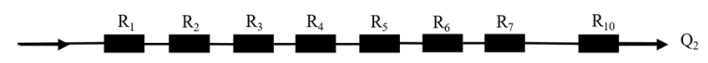

b) Simplified model

$\begin{array}{ll}\text { Component } & \text { Descriptions } \\ \mathrm{Q}_{1} & \text { Evaporator heat input } \\ \mathrm{R}_{1} & \text { Evaporator wall in radial direction } \\ \mathrm{R}_{2} & \text { Evaporator wick in radial direction } \\ \mathrm{R}_{3} & \text { Evaporation } \\ \mathrm{R}_{4} & \text { Axial flow of steam } \\ \mathrm{R}_{5} & \text { Condensation } \\ \mathrm{R}_{6} & \text { Condenser wick in radial direction } \\ \mathrm{R}_{7} & \text { Condenser wall in radial direction } \\ \mathrm{R}_{8} & \text { Adiabatic wick in axial direction } \\ \mathrm{R}_{9} & \text { Adiabatic wall in axial direction } \\ \mathrm{R}_{10} & \text { Convective cooling condition } \\ \mathrm{Q}_{2} & \text { Condenser heat output }\end{array}$

Figure. 1 Equivalent thermal resistance system for the mercury heat pipe operation

$\mathrm{R}_{1}-\mathrm{R}_{2}$ are shown in Eqs. (1-7) respectively:

$$
\begin{gathered}
R_{1}=\frac{\ln \left(d_{o} / d_{i}\right)}{2 \pi \lambda_{w a} L_{e}} \\
R_{2}=\frac{\ln \left(d_{\mathrm{i}} / d_{v}\right)}{2 \pi \lambda_{w i} L_{e}} \\
R_{3}=\frac{R T_{v}^{2} \sqrt{2 \pi R T_{v}}}{r^{2} p_{v} \pi d_{v} L_{e}} \\
R_{4}=\frac{128 L \mu_{v} T_{v}}{\pi d_{v}^{4} \rho_{v}^{2} h_{f g}} \\
R_{5}=\frac{R T_{v}^{2} \sqrt{2 \pi R T_{v}}}{r^{2} p_{v} \pi d_{v} L_{\mathrm{c}}} \\
R_{6}=\frac{\ln \left(d_{\mathrm{i}} / d_{v}\right)}{2 \pi \lambda_{v i} L_{\mathrm{c}}} \\
R_{7}=\frac{\ln \left(d_{o} / d_{i}\right)}{2 \pi \lambda_{w a} L_{\mathrm{c}}}
\end{gathered}
$$

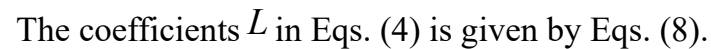

$$
L=L_{a}+\left(L_{e}+L_{c}\right) / 2
$$

$R_{10}$ is shown in Eqs. (9)

$$
R_{10}=\frac{1}{\pi \alpha d_{o} L_{\mathrm{c}}}
$$

Where $d_{v}, d_{i}, d_{o}$ represent the diameter of steam cavity, inner diameter and outer diameter of tube wall, respectively [m]. $L_{e}, L_{a}, L_{c}, L_{\text {represents the length of }}$ evaporation section, adiabatic section, condensing section and effective length of heat pipe, respectively [m]. $\lambda_{w a}, \lambda_{w i}$ represent the thermal conductivity of the wall and wick of the heat pipe, respectively $\mathrm{W} /(\mathrm{m} \cdot \mathrm{K}) . R$ represents the vapor gas constant, $\mathrm{J} /(\mathrm{mol} \cdot \mathrm{K}) . T_{v}, p_{v}$ represent the saturated temperature $\mathrm{K}$ and pressure of steam $\mathrm{Pa}$, respectively.

\subsection{Structural parameters of mercury heat pipe}

The parameters of mercury heat pipe in this paper are shown in Table 1.

Table 1 Structural parameters of mercury heat pipe

\begin{tabular}{ll}
\hline Parameter & Value \\
\hline Material of heat pipe wall & $316 \mathrm{~L}$ \\
Material of wick structure & $316 \mathrm{~L}$ \\
Thickness of wick $(\mathrm{mm})$ & 0.5 \\
Thickness of heat pipe wall $(\mathrm{mm})$ & 2 \\
Outer diameter of heat pipe $(\mathrm{mm})$ & 20 \\
Porosity of the wick structure & 0.7 \\
Length of the evaporator $(\mathrm{mm})$ & 500 \\
Length of the insulation section $(\mathrm{mm})$ & 200 \\
Length of the condenser $(\mathrm{mm})$ & 300 \\
\hline
\end{tabular}

\subsection{Verification of mercury heat pipe model}

In order to verify the effectiveness of the model, the model is used to calculate the mercury heat pipe in reference [13], and the results are compared with the reference experimental data. Table 2 and 3 shows the comparison of evaporator and condenser temperature between experimental data and calculated data for different power respectively. It can be seen from the table below that the calculated data are in good agreement with the experimental data, and the maximum relative error is $3.3 \%$, which proves the effectiveness of the model in this paper.

Table 2 Comparison of evaporator temperature between experimental data and calculated data

\begin{tabular}{llll}
\hline Power & $\begin{array}{l}\text { Calculation } \\
\text { data }\end{array}$ & $\begin{array}{l}\text { Experimental } \\
\text { data }\end{array}$ & $\begin{array}{l}\text { Relative } \\
\text { error }\end{array}$ \\
\hline 700 & 627.82 & 629.83 & $0.32 \%$ \\
1350 & 758.08 & 758.89 & $0.1 \%$ \\
2080 & 861.05 & 864.48 & $0.4 \%$ \\
2380 & 911.91 & 911.37 & $0.1 \%$ \\
\hline
\end{tabular}

Table 3 Comparison of condenser temperature between experimental data and calculated data

\begin{tabular}{llll}
\hline Power & $\begin{array}{l}\text { Calculation } \\
\text { data }\end{array}$ & $\begin{array}{l}\text { Experimental } \\
\text { data }\end{array}$ & $\begin{array}{l}\text { Relative } \\
\text { error }\end{array}$ \\
\hline 700 & 625.58 & 605.11 & $3.3 \%$ \\
1350 & 753.77 & 728.73 & $3.3 \%$ \\
2080 & 854.4 & 839.00 & $1.8 \%$ \\
2380 & 904.3 & 886.83 & $1.9 \%$ \\
\hline
\end{tabular}




\section{Results and discussion}

In this study, the performance of mercury heat pipe was studied by using alternating power, and the influence of amplitude and period of alternating power were investigated respectively. The constant power is $1000 \mathrm{~W}$, the alternating power are $750 \mathrm{~W} / 1250 \mathrm{~W}, 500 \mathrm{~W} / 1500 \mathrm{~W}$, $250 \mathrm{~W} / 1750 \mathrm{~W}$ respectively, and the time period are $1 \mathrm{~min}$, $2 \mathrm{~min}, 5 \mathrm{~min}$ and $10 \mathrm{~min}$ respectively.

\subsection{Start up performance of mercury heat pipe during alternating power}

Figure. 2 shows the change of the temperature of the mercury heat pipe with time when the heat pipe starts up at constant power of $1000 \mathrm{~W}$. It can be clearly seen that when the heat pipe is heated, the evaporator temperature and condenser temperature basically rise synchronously. This is mainly because mercury heat pipe can establish continuous flow at room temperature. With increasing heating time, the temperature difference between evaporator and condenser increases and finally stabilizes. From the speed of temperature rise, in the early stage of heating, due to the low temperature difference between the heat pipe condenser and the heat sink, Most heat flux is used for its own storage of the heat pipe. Therefore, the temperature rise basically presents a linear function. With the increase of time, the temperature difference between the heat pipe condenser and the heat sink increases, and the heat storage speed of the heat pipe itself decreases, so the speed of temperature rise increases gradually slowed down,which shows a parabolic rise, and tends to be stable finally.

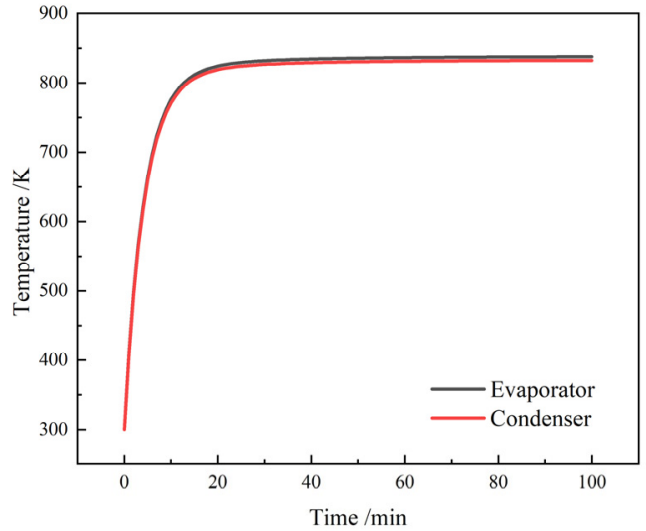

Figure. 2 Temperature change of heat pipe with time under constant power

Figure. 3 shows the change of heat pipe temperature with time under the condition of $500 \mathrm{~W} / 1500 \mathrm{~W}$ alternating power and $1 \mathrm{~min}$ time period. It can be clearly seen that the evaporator temperature and condenser temperature rise almost synchronously, which shows that the alternating power does not affect the normal start-up of the heat pipe. In the early stage, the temperature of both evaporator and condenser fluctuates, but the fluctuation is relatively small. With the increase of heating time, the fluctuation intensifies. And when the heat pipe reached a stable situation, the amplitude of the fluctuation reaches the maximum. From the start-up time, the time under alternating power is basically the same as that under constant power.

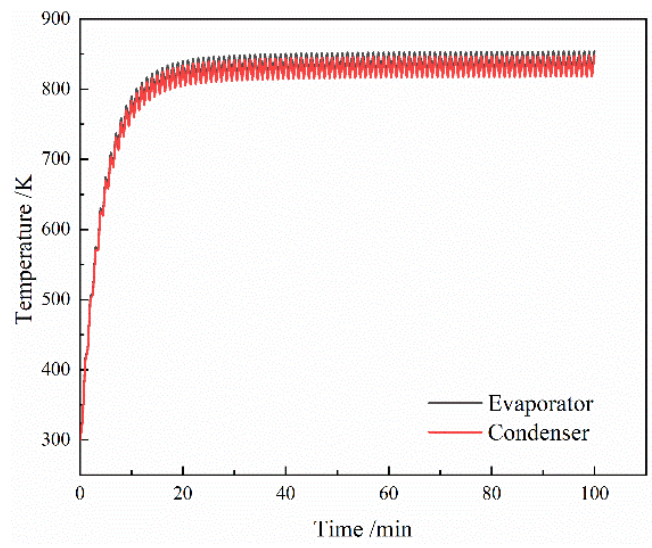

Figure. 3 Temperature of the heat pipe changes with time under $500 \mathrm{~W} / 1500 \mathrm{~W}$ and $1 \mathrm{~min}$ period

Figure. 4 shows the temperature change of the heat pipe evaporator with time under alternating power and its corresponding limit power. From the temperature start-up curve, the start-up rate, start-up time and stable temperature of heat pipe under alternating power are between under the upper and lower limit power.

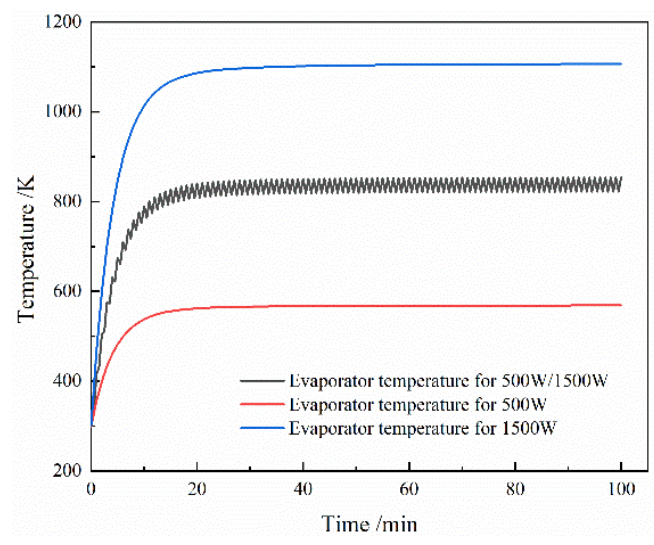

Figure. 4 Temperature change of the heat pipe evaporator with time under alternating power and its corresponding limit power

\subsection{Steady performance of mercury heat pipe during alternating power}

\subsubsection{Influence of alternating power on temperature}

Figure. 5 shows the temperature variation of the heat pipe evaporator for different alternating period under 500W / $1500 \mathrm{~W}$ alternating power. From each alternating period, the temperature of the heat pipe evaporator fluctuates with time, and the maximum and minimum values are far less than the corresponding limiting power.This is because the alternating period is short and the heat pipe has not reached the stable temperature value. From different alternating periods, the symmetrical value of temperature fluctuation of heat pipe evaporator under alternating power is basically the same and equal to the stable temperature value of $1000 \mathrm{~W}$. The fluctuation of evaporator temperature increases with the increase of alternating period. 


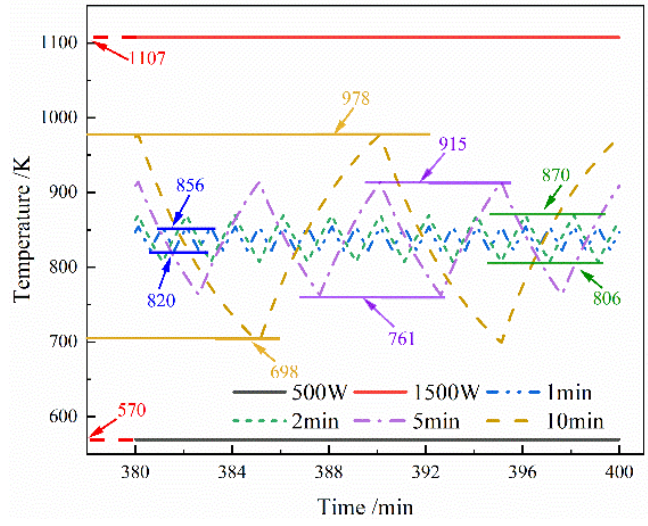

Figure. 5 Temperature variation of the heat pipe evaporator for different alternating period under $500 \mathrm{~W} / 1500 \mathrm{~W}$

Figure. 6 shows the variation of evaporator maximum temperature for different alternating period under $500 \mathrm{~W} /$ $1500 \mathrm{~W}$. With increasing alternating period, the maximum temperature of evaporator increases. When the alternating period is $1 \mathrm{~min}$, the maximum temperature of the heat pipe evaporator increases by $18 \mathrm{~K}$ relative to the constant power. And when the alternating period increases to 10 min, the maximum temperature increases to $140 \mathrm{~K}$. This is mainly becasue the increase of the operation time of the heat pipe at a certain heating power and the heat pipe can reach a higher temperature when the alternating period increases.

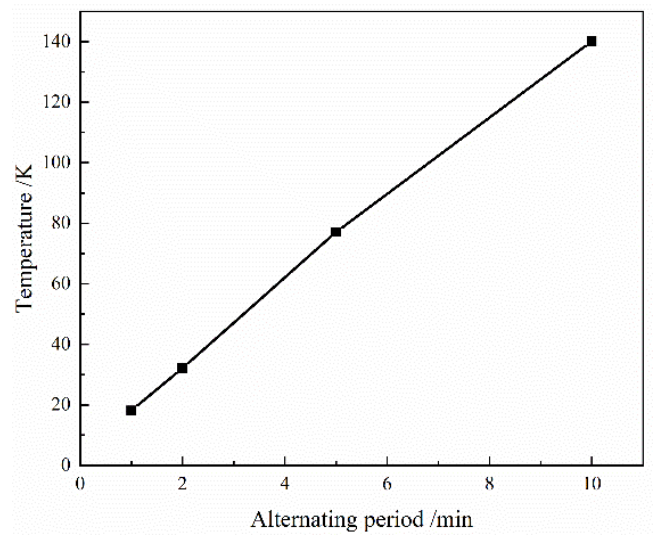

Figure. 6 Variation of evaporator maximum temperature for different alternating period under $500 \mathrm{~W} / 1500 \mathrm{~W}$

Figure. 7 shows the proportion of maximum temperature increment of heat pipe evaporator to limit increment for different alternating period under 500W / $1500 \mathrm{~W}$. When the alternating period is $1 \mathrm{~min}$, the proportion is around $5 \%$; when the alternating period is 10 min, the proportion increases to $42 \%$.

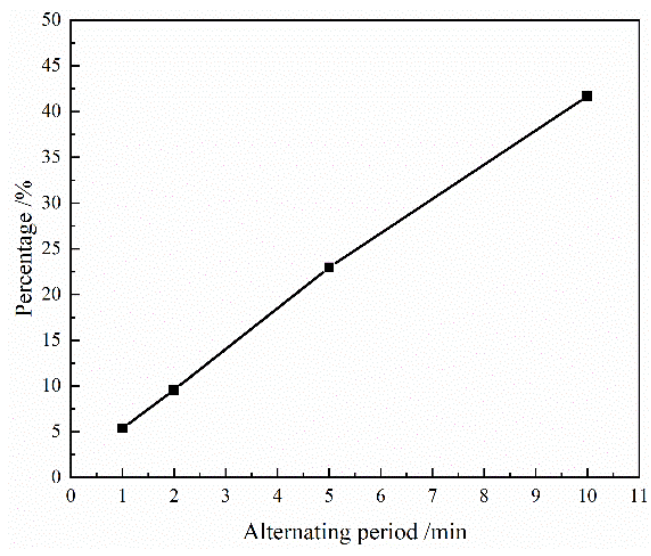

Figure. 7 The proportion of maximum temperature increment of heat pipe evaporator to limit increment for different alternating period under $500 \mathrm{~W} / 1500 \mathrm{~W}$

Figure. 8 shows the temperature of heat pipe evaporator for different amplitude of the alternating power at $1 \mathrm{~min}$ period. From different alternating amplitudes, with increasing alternating power amplitude, the fluctuation of heat pipe evaporator increases, and the period of fluctuation consistent with that of alternating power.

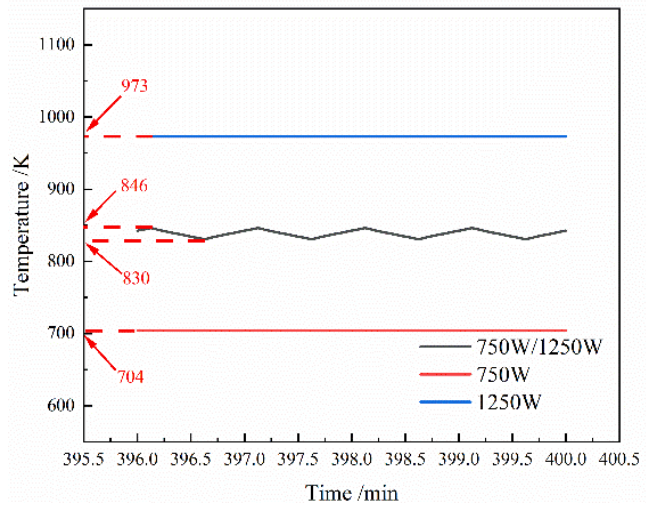

a) $750 \mathrm{~W} / 1250 \mathrm{~W}$

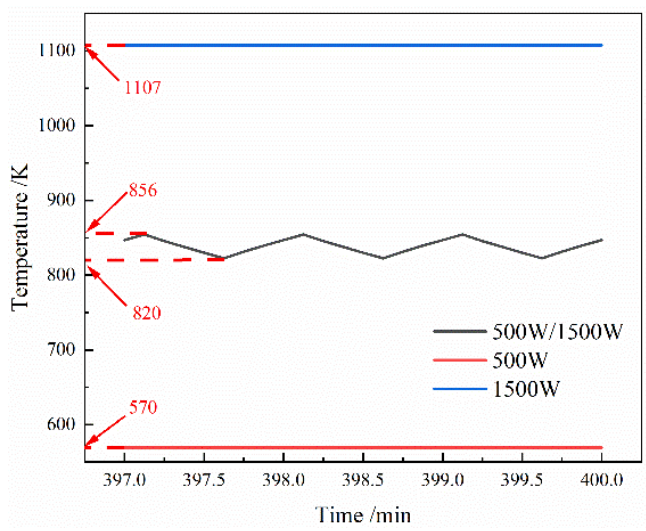

b) $500 \mathrm{~W} / 1500 \mathrm{~W}$ 


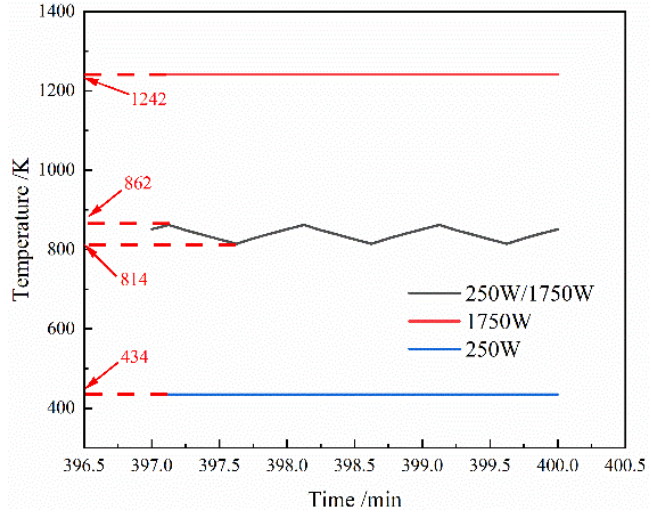

c) $250 \mathrm{~W} / 1750 \mathrm{~W}$

Figure. 8 Temperature of heat pipe evaporator for different amplitude of the alternating power

Figure. 9 shows the influence of different alternating power amplitude on maximum temperature increment of evaporator.When the amplitude is $250 \mathrm{~W}$, the maximum temperature increase is $8 \mathrm{~K}$, and when the amplitude is 750 , the temperature increase reaches $24 \mathrm{~K}$.

Figure. 10 shows the percentage of the maximum temperature increase of evaporator in the limit increase for different amplitude. It can be seen that different alternating power amplitudes have little effect on its percentage.

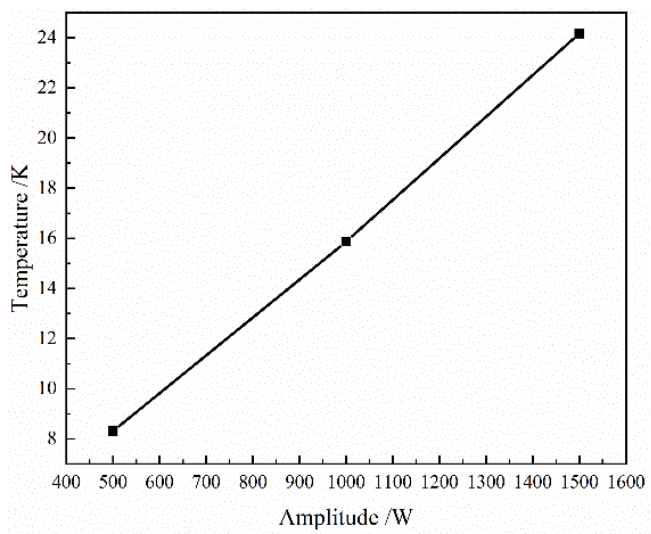

Figure. 9 Maximum temperature increment of evaporator for different amplitude

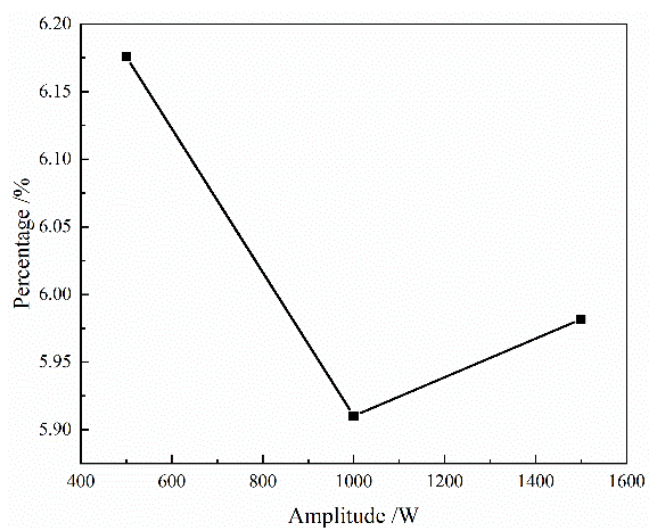

Figure. 10 Percentage of the maximum temperature increase of evaporator in the limit increase for different amplitude

\subsubsection{Influence of alternating power on thermal resistance}

Figure. 11 shows the thermal resistance of the heat pipe for different amplitudes. From each alternating amplitude, the thermal resistance changes periodically. From different amplitudes, with increasing amplitude, the amplitude of thermal resistance increases. The minimum thermal resistance decreases slightly, while the maximum increases greatly. When the amplitude is $500 \mathrm{~W}$, the maximum thermal resistance is around 1.5 times that of constant power. And when the amplitude increases to $1500 \mathrm{~W}$, the maximum thermal resistance increases to 4 times. From the average value of thermal resistance, the average value increases with the increase of the amplitude. When the amplitude is $500 \mathrm{~W}$, the average value of thermal resistance is almost the same as that of constant heating power. However, When the amplitude is $1500 \mathrm{~W}$, the average value is about twice of constant heating power.

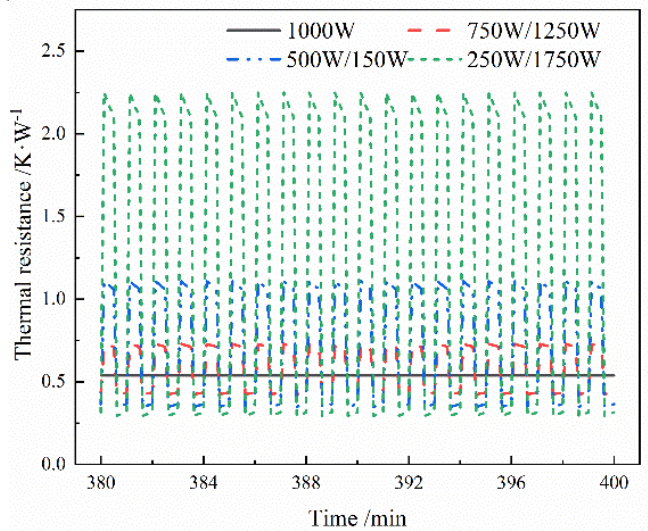

Figure. 11 Thermal resistance of the heat pipe for different amplitudes

Figure. 12 shows the thermal resistance of the heat pipe for different alternating period. From different alternating power periods, with the increasing alternating power period, the alternating period of thermal resistance increases and the maximum and average values of thermal resistance increase slightly.

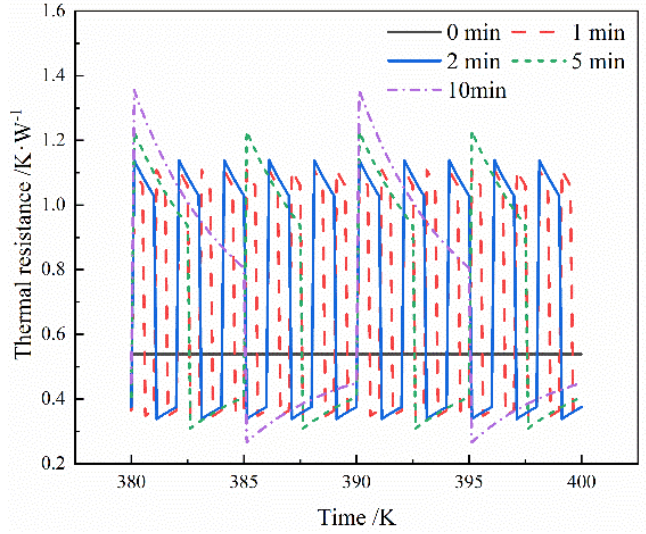

Figure. 12 Thermal resistance of the heat pipe for different alternating period

\section{Conclusion}

In this paper, the effect of alternating power heating on the start-up and heat transfer performance of mercury heat 
pipe is studied.The results are as follows.

1) Compared with the constant power heating, the temperature of the mercury heat pipe fluctuates during the start-up process of alternating power heating, but the start-up time changes little.

2) The temperature of the mercury heat pipe during the steady-state of alternating power heating fluctuates around that during the constant heating power, and the average fluctuation temperature is basically consistent with the constant power. With the increase of the alternating period, the fluctuation amplitude increases. When the period increases to $10 \mathrm{~min}$, the maximum temperature of the heat pipe evaporator increases by $140 \mathrm{~K}$ relative to that of constant power. With the increase of amplitudes, the fluctuation amplitude of heat pipe temperature increases. When the amplitude increases to $1500 \mathrm{~W}$, the maximum temperature of the evaporator increases $24 \mathrm{~K}$ relative to the constant power.

3) The maximum thermal resistance is about 4 times that of the constant power, and the average value of the maximum alternating thermal resistance is 2 times that of the constant power. Increasing the alternating period will increase the fluctuation amplitude of the alternating thermal resistance slightly.

\section{Acknowledgments}

This work was supported by the key projects of natural science research in Anhui Province (Grant No. KJ2020A0730), The teaching Studio (Grant No. 2016msgzs071), The open research platform project of Suzhou University (Grant No. 2020ykf14). The Key projects of Suzhou University (Grant No. 2020yzd08).

\section{References}

1. Weng Y C , Cho H P, Chang C C , et al. Heat pipe with PCM for electronic cooling[J]. Applied Energy, 2011, 88( 5):1825-1833.

2. Riffat S B, Zhao X, Doherty P S . Developing a theoretical model to investigate thermal performance of a thin membrane heat-pipe solar collector[J]. Applied Thermal Engineering, 2005, 25(5-6):899915.

3. Steeves, O.A., He, M.Y., Kasen, S.D., Valdevit, L. and Wadley, H.N.G. (2009) Feasibility of Metallic Structural Heat Pipes as Sharp Leading Edges for Hypersonic Vehicles. ASME Journal of Applied Mechanics, 76.

4. Chatterjee, A., Wayner, P.C., Plawsky, J.L., Chao, D.F., Sicker, R.J., Lorik, T., et al. (2011) The Constrained Vapor Bubble Fin Heat Pipe in Microgravity. Industrial Engineering Chemistry Research, 50, 8917-8926.

5. Enke C, Jorge Bertoldo Júnior, Vlassov V. Transient response of an axially-grooved aluminum-ammonia heat pipe with the presence of non-condensable gas[J].
Applied Thermal Engineering, 2021, 183:116135.

6. Wang C, Zhang L, Liu X, et al. Experimental study on startup performance of high temperature potassium heat pipe at different inclination angles and input powers for nuclear reactor application $[\mathrm{J}]$. Annals of nuclear energy, 2020, 136(Feb.):107051.1-107051.8.

7. Teng W, Wang X, Zhu Y. Experimental investigations on start-up and thermal performance of sodium heat pipe under swing conditions[J]. International Journal of Heat and Mass Transfer, 2020, 152(May):119505.1-119505.8.

8. Miao S, Sui J, Zhang Y, et al. Experimental Study on Thermal Performance of a Bent Copper-Water Heat Pipe[J]. International Journal of Aerospace Engineering, 2020, 2020(4):1-10.

9. $\mathrm{Xu} \mathrm{H}$, Zhang H, Ding L, et al. Effect of solar radiation on heat transfer of high temperature heat pipe solar power receiver $[\mathrm{J}]$. Journal of Nanjing University of Technology: Natural Science Edition , 2009, 31 (5): 91-95.(in chinese)

10. Shen $\mathrm{Y}$, Zhang $\mathrm{H}, \mathrm{Xu} \mathrm{H}$, et al. Heat transfer characteristics of high temperature heat pipe with triangular grooved wick under variable heat fluxes.(in chinese)

11. P. D. Dunn, D. A. Reay, Heat Pipes, New York, Pergamon, 1978. 